\title{
UV Written 2x8 Optical Power Splitter for FTTH Applications
}

\section{Olivero, Massimo; Svalgaard, Mikael}

Published in:

Optical Fiber Communication Conference Technical Digest

Link to article, DOI:

10.1109/OFC.2006.215472

Publication date:

2006

Document Version

Publisher's PDF, also known as Version of record

Link back to DTU Orbit

Citation (APA):

Olivero, M., \& Svalgaard, M. (2006). UV Written 2x8 Optical Power Splitter for FTTH Applications. In Optical Fiber Communication Conference Technical Digest (pp. OWF3). IEEE.

https://doi.org/10.1109/OFC.2006.215472

\section{General rights}

Copyright and moral rights for the publications made accessible in the public portal are retained by the authors and/or other copyright owners and it is a condition of accessing publications that users recognise and abide by the legal requirements associated with these rights.

- Users may download and print one copy of any publication from the public portal for the purpose of private study or research.

- You may not further distribute the material or use it for any profit-making activity or commercial gain

- You may freely distribute the URL identifying the publication in the public portal

If you believe that this document breaches copyright please contact us providing details, and we will remove access to the work immediately and investigate your claim 


\title{
UV Written $2 \times 8$ Optical Power Splitter for FTTH Applications
}

\author{
Massimo Olivero* and Mikael Svalgaard \\ COM, Technical University of Denmark, 2800 Lyngby, Denmark, \\ Phone: (+45) 4525 6391, Fax: (+45) 45936581 , \\ svlgrd@com.dtu.dk \\ "Presently at PhotonLab, Politecnico di Torino, 10129 Torino, Italy, \\ Phone: (+39) 0112276301 , Fax:(+39) 0112276309 , \\ massimo.olivero@polito.it
}

\begin{abstract}
Silica based integrated optical $2 \times 8$ power splitters are reported for the first time using UV-writing waveguide fabrication technology. High performance, compactness and low production costs make these components well suited for deployment in FTTH networks.

(C)2006 Optical Society of America

OCIS codes: (230.1360) Beam splitters; (130.3120) Integrated optics devices; (250.5300) Photonic integrated circuits; (160.5320) Photorefractive materials; (230.7390) Waveguides, planar; (260.7190) Ultraviolet.
\end{abstract}

\section{Introduction}

Low cost integrated optical $2 \times 8$ power splitters are important components for Fiber-To-The-Home (FTTH) applications since passive optical networks require splitters with double input to create a redundant path and increase the network security [1]. Hence the present work has focused on the development of such components by means of direct writing with a focussed UV laser beam in photosensitive glass samples [2], where costly photolithographic and etching processes are avoided.

We report on the fabrication of a number of $2 \times 8$ broadband splitters consisting of a broadband coupler and Ybranch splitter sections. The layout has been optimized for compactness and low loss. Performance in terms of loss and uniformity are nearly within commercial specifications in the wavelength range $1300-1750 \mathrm{~nm}$.

\section{Fabrication}

The splitters are fabricated in three layer silica-on-silicon samples with a $5.4 \mu \mathrm{m}$ thick, $\mathrm{Ge} / \mathrm{B}$ doped core layer. The samples are loaded with deuterium at 500 bar until saturation prior to UV writing to enhance the photosensitivity. Channel waveguides are written into the core layer by scanning the sample under a continuous-wave, focused UV beam using high-precision translation stages [3]. The stages are computer controlled with an interferometric position measurement feedback loop. The UV beam has a wavelength of $257 \mathrm{~nm}$ and may be blocked using a shutter as required in the scanning process. The incident beam power is $45 \mathrm{~mW}$, which is focused on the core layer to a $1 / \mathrm{e}^{2}$ spot size of $3.1 \mu \mathrm{m}$. After UV writing the samples are annealed at $80{ }^{\circ} \mathrm{C}$ for 12 hours to outdiffuse residual deuterium, then subjected to a second annealing at $320^{\circ} \mathrm{C}$ for 3 hours to reduce the index step so that single mode operation is achieved in the $1300 \mathrm{~nm}$ and $1500 \mathrm{~nm}$ windows and the thermal stability is increased. Most of the circuit is written with a scan velocity of $280 \mu \mathrm{m} / \mathrm{s}$, which yields a waveguide width of $6.1 \mu \mathrm{m}$ and an index step after annealing of 0.0085 .

\section{Design and layout}

The layout of the fabricated $2 \times 8$ splitters is depicted in Fig. 1(a). Two input channels are combined through an asymmetrical broadband directional coupler [4], which is written in two scans. An asymmetric structure in the central coupling region with a wavelength flattened response is achieved by locally decreasing the scan velocity in the first arm while increasing it in the second arm. It has been found experimentally that scan velocities of $100 \mu \mathrm{m} / \mathrm{s}$ and $900 \mu \mathrm{m} / \mathrm{s}$, a center-to-center waveguide separation of $8 \mu \mathrm{m}$ and $230 \mu \mathrm{m}$ long waveguides in the central coupling region results in a wavelength flattened coupling ratio of $50 \%$.

Each Y-branch section is written in three scans, first an access waveguide followed by two output arms (Fig. 1(b)). The output arms are shaped as a cascade of two S-bends: the first to make an adiabatic taper and the second to achieve the required transverse displacement for connecting to the next section. Each S-bend is shaped as a polynomial function with zero derivatives up to the fourth order in the ends. This minimizes mode mismatching which is typical of other curve types such as the circular arcs [3] or cosine bends previously deployed [5], thereby 


\section{OWF3.pdf}

(a)

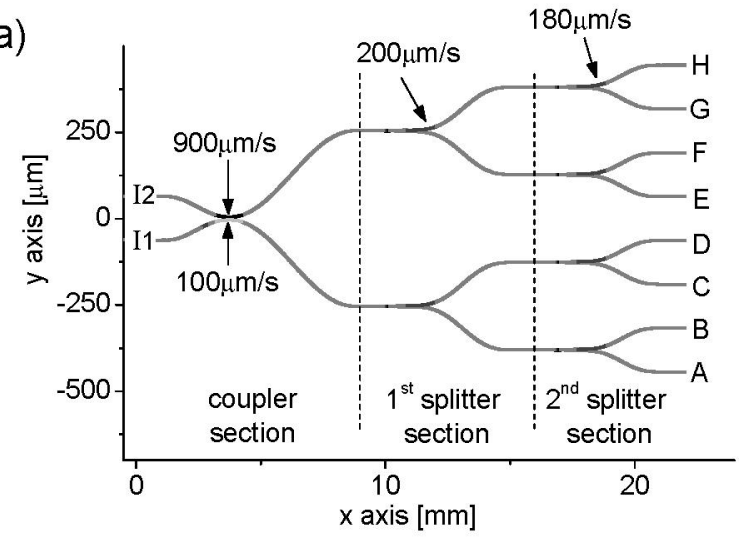

(b)

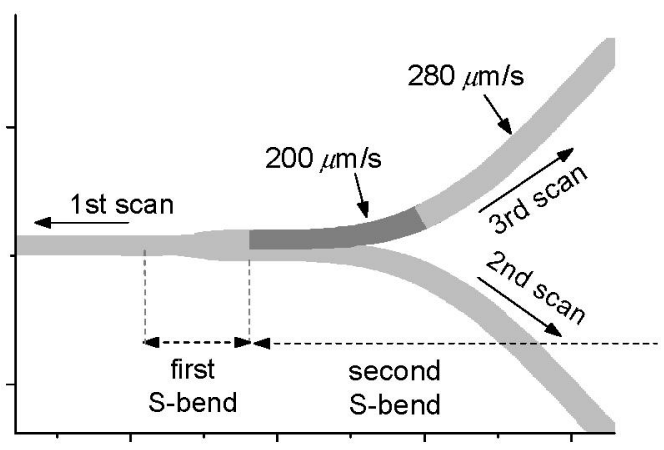

Fig. 1. (a) Overview of $2 \times 8$ splitter layout. (b) Close-up view of a Y-branch in 1 st splitter section

reducing excess loss and improving the channel uniformity. The bend lengths have been chosen so that the minimum radius of curvature is $20 \mathrm{~mm}$, yielding a measured excess loss below $0.03 \mathrm{~dB} / \mathrm{bend}$. Symmetrical splitting is achieved by applying slightly different scan velocities in the central part of each splitter (as indicated in Fig. 1), to compensate for a reduced photosensitivity in the vicinity of a UV exposed area [3].

The output port pitch is $127 \mu \mathrm{m}$ to accommodate commercially available fiber connector arrays. The component is $22 \mathrm{~mm}$ long which, combined with $12 \mathrm{~mm}$ long fiber arrays, yields a pigtailed device that would be roughly $2 / 3$ the size of many commercial components, and thus very well suited for compact system integration. The total UV writing time for a single $2 \times 8$ splitter is 360 seconds.

\section{Performance}

Characterization was carried out using buttcoupled SMF-28 fibers with index-matching oil. The performance of a typical $2 \times 8$ splitter measured at $1557 \mathrm{~nm}$ with a polarized source is summarized in Fig. 2. The dataset for each input port overlap each other and does not exhibit any slope, showing that the coupling and splitter sections are well balanced. The channel loss is $<11.6 \mathrm{~dB}$ and the total excess loss is $1.4 \mathrm{~dB}$, which is similar to that of commercial devices.

The average PDL is $0.7 \mathrm{~dB}$, but for channel $\mathrm{H}$ it rises to $2 \mathrm{~dB}$ with excitation at I1. This phenomenon is seen in many of the fabricated devices, and it does not occur for the same input/output channel each time. The effect only becomes apparent when the guided mode amplitude is low, such as when the input signal is

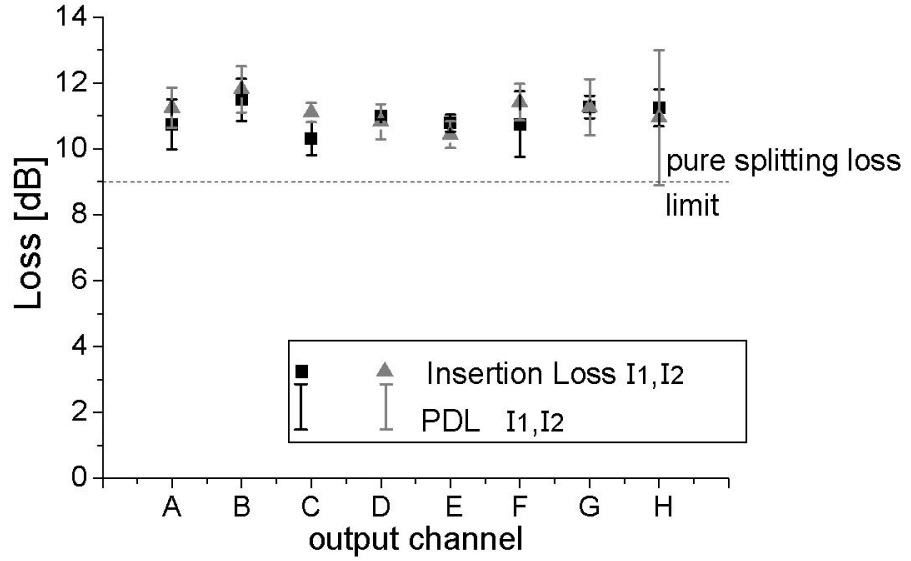

Fig. 2. Insertion loss (symbols) and PDL (vertical bars) of a $2 \times 8$ splitter at 1557 $\mathrm{nm}$ measured for both input ports

distributed among several output channels [5]. It is speculated that weakly guided higher order modes copropagating in the core layer, upon re-coupling to the main mode leads to the observed behavior. A core layer with a refractive index slightly lower than that of the buffer/cladding may greatly reduce the amplitude of co-propagating higher order modes and thus reduce the sporadically high PDL.

Broadband characterization was done with a unpolarized source from $1300-1750 \mathrm{~nm}$. The spectral variation of an isolated asymmetric coupler section is depicted in Fig. 3(a) along with that of a standard symmetrical coupler for comparison. The former exhibits a $\pm 0.5 \mathrm{~dB}$ flatness over the entire wavelength range, while the symmetrical coupler exhibits the same variation over just $80 \mathrm{~nm}$. Broadband measurements of channel loss, uniformity and total excess loss of a complete $2 \times 8$ splitter is shown in Fig. 3(b). The total excess loss over the entire range is $1.6 \mathrm{~dB}$ with a ripple of $\pm 0.2 \mathrm{~dB}$. The uniformity is quite flat and low down to $1400 \mathrm{~nm}$, with a mean value of $1.9 \mathrm{~dB}$ and a ripple of $\pm 0.4 \mathrm{~dB}$. Below $1400 \mathrm{~nm}$ the uniformity rises, most likely due to the increased slope of the coupling ratio shown in 


\section{OWF3.pdf}
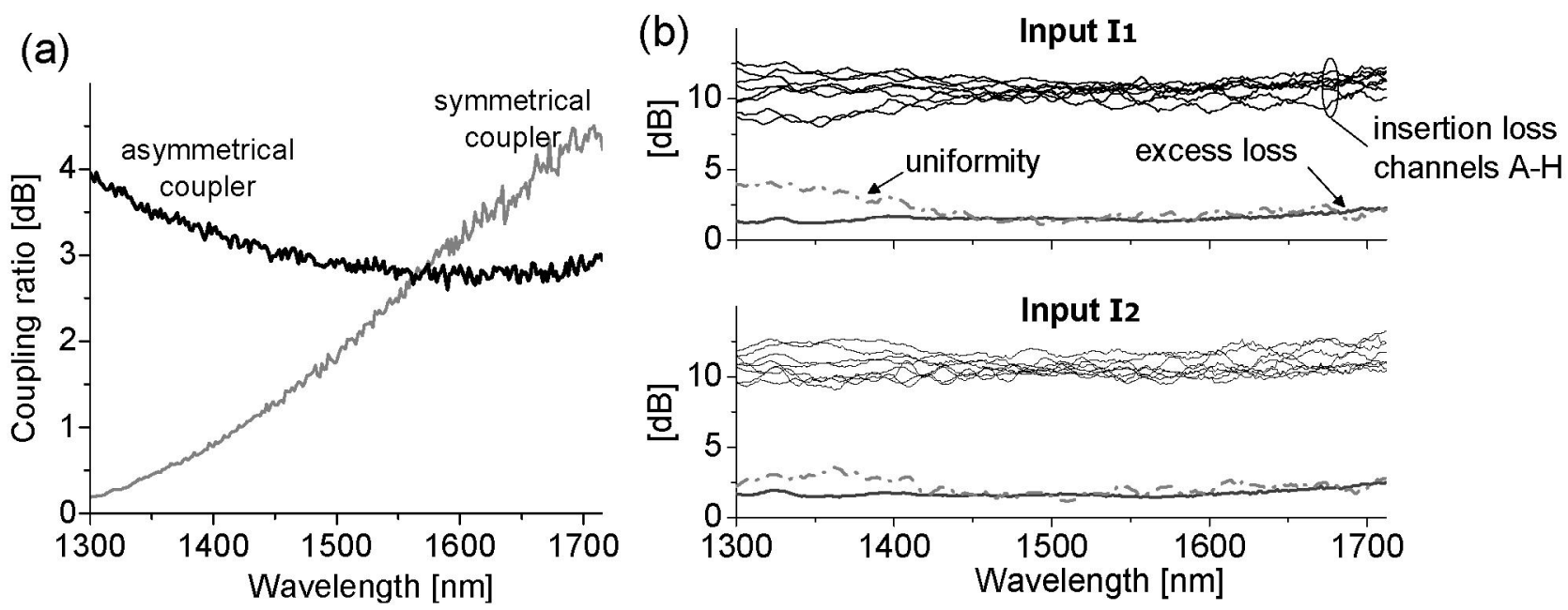

Fig. 3. (a) Spectral variation of isolated coupler (black curve: asymmetrical coupler, grey curve: symmetrical coupler). (b) Broadband measurement of channel insertion loss (black curves), channel uniformity (grey dot-dashed curve) and total excess loss (dark grey curve) for a $2 \times 8$ splitter.

Fig. 3(a). The overall broadband response is similar to top-grade commercial performance both in terms of loss and uniformity in the $\mathrm{C}, \mathrm{L}$ and $\mathrm{E}$ bands. A further improvement of the uniformity can be achieved in the $1300 \mathrm{~nm}$ window by a small optimization of the coupling section, i.e. by shifting the wavelength of the peak coupling ratio from the current $\sim 1600 \mathrm{~nm}$ to $\sim 1500 \mathrm{~nm}$. The degree of broadband operation demonstrated here is achieved due to the combination of an asymmetric coupler design with inherently broadband Y-shaped splitting sections.

The device-to-device fabrication reproducibility is quite good on our research setup with 5 out of 7 measured devices being within the presented specifications. The main source of component failure stems from laser power drift, which is expected to be improved by introduction of an active control of the incident UV power.

\section{Conclusion}

The first demonstration of $2 \times 8$ power splitters made by direct UV writing has been presented. The splitter layout consists of a broadband coupler section followed by Y-branch splitter sections and has been optimized for compactness and low loss. The unique feature of direct UV writing to locally control the index step and width by changing the scan velocity has been exploited to achieve broadband performance. The scan velocities applied in the splitting sections have been optimized to achieve good uniformity among the output channels. The components, showing good performance in terms of loss, uniformity and bandwidth, could find application in FTTH networks.

\section{References}

1. Standards ITU-G 983.5 and ITU-G 983.6, 2002. Available:

http://www.itu.int/rec/recommendation.asp?type-products\&lang=e\&parent=T-REC-G

2. M. Svalgaard, C. V. Poulsen, A. Bjarklev, and O. Poulsen, “ Direct UV-writing of buried single-mode channel waveguides in Ge-doped silica films," Elec. Lett. 30, 1401-1402, (1994).

3. K. Færch, M. Svalgaard, "Symmetrical waveguide device fabricated by direct UV writing," IEEE Photon. Technol. Lett. 14, 173-175, (2002).

4. M. Olivero, M. Svalgaard, "Direct UV-written Broadband Directional Planar Waveguide Couplers," Opt. Express 13 (accepted for publication) (2005).

5. M. Olivero, M. Svalgaard, "UV written $1 \times 8$ optical splitters," in Proceedings of OSA Topical Meeting on Bragg Gratings, Poling and Photosensitivity, B.J. Eggleton, ed., (Technical Digest Series, Optical Society of America, Washington, D.C., 2005 ), 37-38. 